\title{
Survivin Ser81 Plays An Important Role in PI3K/Akt/mTOR Signaling Pathway
}

\author{
Ferry Sandra ${ }^{1,2}$ \\ ${ }^{1}$ Department of Biochemistry and Molecular Biology, Division of Oral Biology, Faculty of Dentistry, Universitas Trisakti, Jakarta, \\ Indonesia \\ ${ }^{2}$ BioCORE Laboratory, Faculty of Dentistry, Universitas Trisakti, Jakarta, Indonesia
}

Background: Survivin, a member of the inhibitor of apoptosis protein family, has been associated with protection from cell apoptosis and regulation of mitosis. Phosphorylated-Survivin at Ser81 was reported to provide cytoprotection against tumor necrosis factor (TNF)-related apoptosis-inducing ligand (TRAIL) in L929 cells by inducing a backloop activation of phosphatidylinositol 3-kinase (PI3K). Therefore Akt as a possible substrate of PI3K was investigated.

Materials and Methods: L929 cells were pretreated with/without $50 \mu \mathrm{M}$ LY294002 or $10 \mu \mathrm{M}$ Perifosine, and infected with viral particle of Survivin, anti sense of Survivin, Ser81Ala mutated Survivin or vector only. Cells were then harvested, lysed and subjected to immunoblot assay to detect Akt, phosphorylated Akt (Ser473), mammalian target of rapamycin (mTOR), phosphorylated-mTOR (Ser2448).

Results: Survivin induced Akt and mTOR phosphorylations in a viral particle concentration dependent manner. Pretreatment of LY294002 or Perifosine prior to Survivin infection, attenuated Akt or mTOR phosphorylations, respectively. Low Akt or mTOR phosphorylations were observed when L929 cells were infected with Ser81Ala mutated Survivin.

Conclusions: Ser81 phosphorylation site of Survivin played an important role in activating Survivin/PKA/PI3K/Akt/mTOR signaling pathway.

Keywords: survivin, Ser81, Akt, mTOR, LY294002, perifosine

\section{Introduction}

Survivin, a member of the inhibitor of apoptosis protein family, has been associated with protection from cell apoptosis and regulation of mitosis. ${ }^{1,2}$ In most finally differentiated adult tissues, Survivin expression is low to undetectable. ${ }^{1,2}$ However, Survivin is overexpressed in advanced cancers pertaining to poor prognosis, high recurrence and resistance to therapy. ${ }^{1,2}$ Survivin was reported

Date of submission: March 30, 2017

Last Revised: April 18, 2017

Accepted for publication: April 18, 2017

Corresponding Author:

Ferry Sandra

Department of Biochemistry and Molecular Biology, Division of Oral Biology

Faculty of Dentistry, Universitas Trisakti, Jl. Kyai Tapa No.260

Jakarta, Indonesia

E-mail: ferrysandra@gmail.com to be involved in all tumor stages, started from initiation, maintenance, until development of tumor. ${ }^{1}$ Therefore, antisurvivin has been suggested as a new approach for cancer therapy. ${ }^{1,2}$

Survivin has been shown to play role in multiple ${ }^{2}$ and back-loop ${ }^{3-5}$ signaling pathways. Survivin could be activated due to its phosphorylation at $\mathrm{Thr} 34^{6}$ and Ser8 $8^{13,7,8}$. Among many other molecules, cyclin B1 and $\mathrm{p} 34^{\mathrm{cdc} 2}$ were reported in activation of Survivin at $\mathrm{Thr} 34^{6}$, while protein 
kinase A (PKA) and phosphatidylinositol 3-kinase (PI3K) were reported in activation of Survivin at Ser $8^{13,7,8}$. Survivin phosphorylation can also occur at Thr53, Thr117 and Ser20. ${ }^{9}$ Inhibition of Survivin phosphorylation by $\mathrm{PH}$ domain leucine-rich repeat protein phosphatase (PHLPP) induces cell apoptosis and exerts anticancer activity in gallbladder cancer. ${ }^{9}$

To date, Survivin has been shown to induce vascular endothelial growth factor (VEGF)/PI3K/Akt, ${ }^{4} \mathrm{PKA} / \mathrm{PI} 3 \mathrm{~K},{ }^{3}$ and PI3K/Akt/hypoxia-inducible factor (HIF)-1 $\alpha$ signaling pathways ${ }^{10}$. However phosphorylation of Survivin, as the keyrole of Survivin activation has not been intensely investigated. Phosphorylation of Survivin at Thr34, $4^{6,11}$ was the mostly investigated, other important phosphorylation sites were Thr $117^{12}$ and Ser8 ${ }^{13,7,8}$. Ser81 of Survivin was reported to provide cytoprotection against tumor necrosis factor (TNF)-related apoptosis-inducing ligand (TRAIL) in L929 cells. ${ }^{7}$ Survivin Ser81 was reported to be important in back-loop Survivin/PKA/PI3K signaling pathway. ${ }^{3}$ Since Akt was reported as the substrate of PI3K in overexpressedSurvivin model ${ }^{4}$, current study was initiated to investigate the possibility of Akt as the downstream of PKA/PI3K in Survivin phosphorylation at Ser81-modulated L929 cells.

\section{Materials and methods}

Survivin constructs, viral production and $L 929$ cells infection

Preparation of Survivin, Antisense Survivin (Survivin-AS) and Ser81Ala mutants (Survivin-S81A) were described in our previous report. ${ }^{1-3}$ Briefly, Survivin, Survivin-AS, Survivin-S81A mutants cDNAs were polymerased, inserted into vector and transfected into BOSC23 cells. BOSC23 cells-produced viruses were harvested and tittered. L929 cells were cultured in $\alpha$-DMEM containing $10 \%$ horse serum. Infection was carried out using viral product of BOSC23 cells (Survivin, Survivin-AS, Survivin-S81A or vector only) for 48 hours.

\section{Cell treatment and lysate preparation}

L929 cells were pretreated with/without $50 \mu \mathrm{M}$ LY294002 (Cell Signaling, Danvers, MA, USA) or $10 \mu \mathrm{M}$ Perifosine (Cell Signaling), and infected with viral particle of Survivin, Survivin-AS, Survivin-S81A or vector only. Cells were then harvested and lysed in a cold lysis buffer $(20 \mathrm{mM}$ Tris- $\mathrm{HCl}$ buffer $\mathrm{pH}$ 8.0, $500 \mathrm{mM} \mathrm{NaCl}, 1$ mM EDTA, 1 mM EGTA, 10 $\mathrm{mM} \beta$-glycerophosphate, $10 \mathrm{mM} \mathrm{NaF}, 10 \mathrm{mM} \mathrm{pNPP}, 0.4 \mathrm{mM}$
Na3VO4, 1 mM benzamidine, $2 \mathrm{mM}$ phenylmethylsulfonyl fluoride, aprotinin, $1 \mathrm{mg} / \mathrm{ml}$ leupeptin, $1 \mathrm{mM}$ dithiothreitol and $10 \%$ Nonidet P-40).

\section{Immunoblot assay}

Samples were separated by SDS-polyacrylamide gel electrophoresis and transferred to a polyvinylidene difluoride sheet. After blocking with 5\% skim milk in Tris-buffered saline, the sheet was incubated with rabbit polyclonal antiAkt (Cell Signaling), rabbit polyclonal anti-phospho-Akt (Ser473) (Cell Signaling), rabbit polyclonal anti-mammalian target of rapamycin (mTOR) (Cell Signaling) or rabbit polyclonal anti-phospho-mTOR (Ser2448) (Cell Signaling) antibody. The secondary antibody was horseradish peroxidase-conjugated goat anti-rabbit IgG antibody (Cell Signaling). The bound antibodies were visualized using Clarity Western ECL (Bio-Rad, Hercules, CA, USA) and captured using Alliance 4.7 (UVItech, Cambridge, UK).

\section{Results}

\section{Survivin induced Akt phosphorylation}

In Figure 1, basal Akt phosphorylation (Ser473) band of L929 cells (upper lane 1 from left) was seen. Upon Survivin infection in concentration of $7.5 \times 10^{7}$ viral particle $/ \mathrm{ml}$, density of Akt phosphorylation (Ser473) band was increased (upper lane 3 from left). Density of Akt phosphorylation (Ser473) band was increased markedly when the cells were infected with Survivin in concentration of $75 \times 107$ viral particle/ml (upper lane 4 from left). Similar band densities of Akt were observed for all lower lanes, showing that the same volume of proteins were electrophorated and detected.

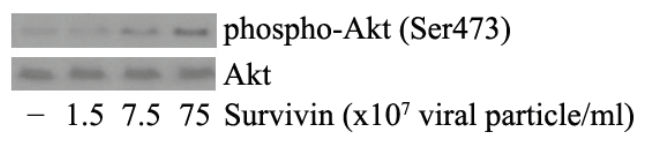

Figure 1. Survivin induced Akt phosphorylation. L929 cells were infected with/without $1.5-75 \times 107$ viral particle/ml retrovirus of Survivin for 48 hours. Infected cells were then lysed and immunoblotted using anti-Akt or anti-phospho-Akt (Ser473) antibody. Detailed procedures are described in "Materials and Methods". Each panel shows the typical result of 3 independent results.

\section{Survivin induced Akt phosphorylation via PI3K}

In Figure 2, high density bands of Akt phosphorylation (Ser473) were observed when L929 cells were infected with $75 \times 10^{7}$ viral particle/ml retrovirus of Survivin with/ 
without pretreatment of DMSO (upper lane 4 and 2 from left, respectively). Meanwhile, pretreatment of LY294002 prior to infection with $75 \times 10^{7}$ viral particle/ml retrovirus of Survivin, resulted a low density band of Akt phosphorylation (Ser473) (upper lane 3 from left). Similar band densities of Akt were observed for all lower lanes, showing that the same volume of proteins were electrophorated and detected.

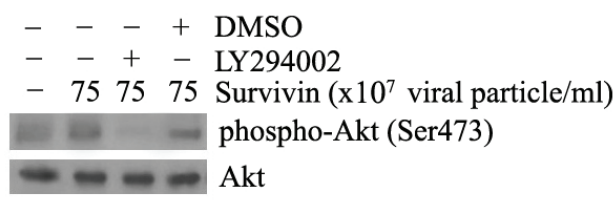

Figure 2. Survivin induced Akt phosphorylation via PI3K. L929 cells were pretreated with/without $50 \mu \mathrm{M}$ LY294002 for 2 hours prior to infection with/without $75 \times 10^{7}$ viral particle $/ \mathrm{ml}$ retrovirus of Survivin for 48 hours as indicated in the panel. Cells were lysed and immunoblotted using anti-Akt or anti-phospho-Akt (Ser473) antibody. DMSO was used as negative control. Detailed procedures are described in "Materials and Methods". Each panel shows the typical result of 3 independent results.

\section{Survivin Ser81 in Akt phosphorylation}

Low density bands of Akt phosphorylation (Ser473) were observed when L929 cells were not infected, infected with vector merely, infected with $75 \times 10^{7}$ viral particle/ $\mathrm{ml}$ retrovirus of Survivin-AS and infected with $75 \times 10^{7}$ viral particle/ml retrovirus of Survivin-S81A, as shown in Figure 3 (upper lane 1, 2, 4 and 5 from left, respectively). Meanwhile, a high density band of Akt phosphorylation (Ser473) was observed when L929 cells were infected with $75 \times 107$ viral particle $/ \mathrm{ml}$ retrovirus of Survivin (upper lane 3 from left). Similar band densities of Akt were observed for all lower lanes, showing that the same volume of proteins were electrophorated and detected.

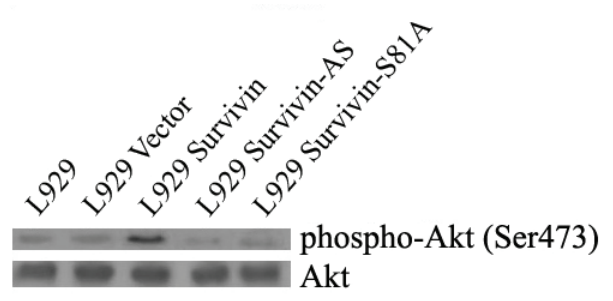

Figure 3. Survivin Ser81 in Akt phosphorylation. L929 cells were infected with $75 \times 10^{7}$ viral particle $/ \mathrm{ml}$ retrovirus of Survivin, Survivin-AS, Survivin-S81A or vector merely for 48 hours. Infected cells were then lysed and immunoblotted using anti-Akt or anti-phospho-Akt (Ser473) antibody. Detailed procedures are described in "'Materials and Methods". Each panel shows the typical result of 3 independent results.

\section{Survivin induced mTOR phosphorylation via Akt}

In Figure 4, density of mTOR phosphorylation (Ser2448) band was increased upon Survivin infection in concentration of $7.5 \times 10^{7}$ viral particle/ml (upper lane 3 from left). Density of mTOR phosphorylation (Ser2448) band was increased markedly when the cells were infected with Survivin in concentration of $75 \times 10^{7}$ viral particle/ml (upper lane 4 from left). A high density band of mTOR phosphorylation (Ser2448) was also observed when L929 cells were infected with $75 \times 10^{7}$ viral particle $/ \mathrm{ml}$ retrovirus of Survivin with pretreatment of ethanol (upper lane 6 from left). Meanwhile, pretreatment of Perifosine prior to infection with $75 \times 10^{7}$ viral particle/ml retrovirus of Survivin, resulted a low density band of mTOR phosphorylation (Ser2448) (upper lane 5 from left). Similar band densities of mTOR were observed for all lower lanes, showing that the same volume of proteins were electrophorated and detected.

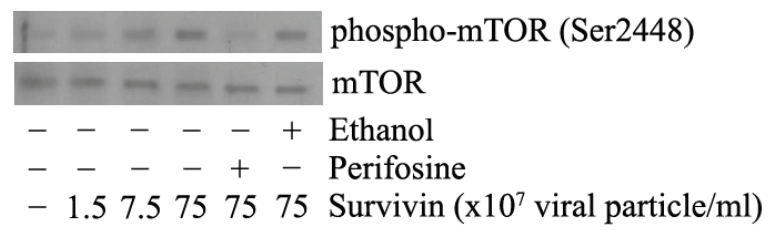

Figure 4. Survivin induced mTOR phosphorylation via Akt. L929 cells were pretreated with/without $10 \mu \mathrm{M}$ Perifosine for 1 hour prior to infection with/without $1.5-75 \times 10^{7}$ viral particle/ $\mathrm{ml}$ retrovirus of Survivin for 48 hours as indicated in the panel. Cells were lysed and immunoblotted using anti-mTOR or anti-phospho-mTOR (Ser2448) antibody. Detailed procedures are described in "Materials and Methods". Ethanol was used as negative control. Each panel shows the typical result of 3 independent results.

\section{Survivin Ser81 in mTOR phosphorylation}

Low density bands of mTOR phosphorylation (Ser2448) were observed when L929 cells were not infected, infected with vector merely, infected with $75 \times 10^{7}$ viral particle/ $\mathrm{ml}$ retrovirus of Survivin-AS and infected with $75 \times 10^{7}$ viral particle/ml retrovirus of Survivin-S81A, as shown in Figure 5 (upper lane 1, 2, 4 and 5 from left, respectively). Meanwhile, a high density band of mTOR phosphorylation (Ser2448) was observed when L929 cells were infected with $75 \times 10^{7}$ viral particle/ml retrovirus of Survivin (upper lane 3 from left). Similar band densities of mTOR were observed for all lower lanes, showing that the same volume of proteins were electrophorated and detected. 


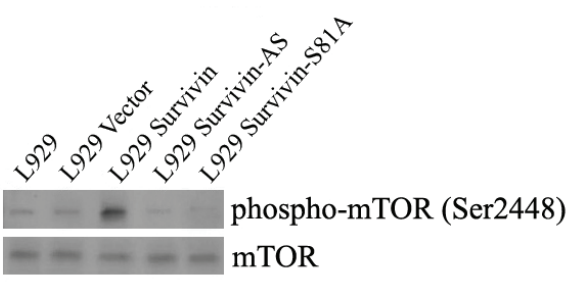

Figure 5. Survivin Ser81 in mTOR phosphorylation. L929 cells were infected with $75 \times 10^{7}$ viral particle $/ \mathrm{ml}$ retrovirus of Survivin, Survivin-AS, Survivin-S81A or vector merely for 48 hours. Infected cells were then lysed and immunoblotted using anti-mTOR or anti-phospho-mTOR (Ser2448) antibody. Detailed procedures are described in "'Materials and Methods". Each panel shows the typical result of 3 independent results.

\section{Discussion}

Current results showed that Survivin induced Akt phosphorylation at Ser473 in a concentration dependent manner. By pretreatment of LY294002, a PI3K inhibitor, the Akt phosphorylation was diminished, suggesting that PI3K was the upstream of Survivin-induced Akt phosphorylation. These results were in accordance to previous reports, ${ }^{4,10}$ that Survivin induced PI3K/Akt signaling pathway. In vector-infected and Survivin-AS-infected L929 cells, the Akt phosphorylation bands were not clearly seen, showing that the phosphorylation was induced specifically by Survivin. In addition, Akt phosphorylation was not clearly seen in Survivin S81A-infected L929 cells, showing that Ser81 phosphorylation site of Survivin is important in this signaling pathway.

$\mathrm{PI} 3 \mathrm{~K} /$ Akt constitute an important pathway regulating the signaling of multiple biological processes such as apoptosis, metabolism, cell proliferation and cell growth..$^{13,14}$ Components related to PI3K/Akt pathway have been reported widely as causal factors in cancer. ${ }^{13-15}$ Activation of PI3K and Akt are reported to occur in breast, ovarian, blood, pancreatic, esophageal, gallbladder and other cancers. ${ }^{13,14}$

mTOR, one of the downstream of Akt, has been widely reported. PI3K/Akt/PTEN/mTOR signaling pathway plays a crucial role in regulating a broad range of cellular functions including cell growth, proliferation, cell survival, angiogenesis, invasion and migration, apoptosis, autophagy, cell cycle, DNA repair, chemoresistance and radioresistance in cancer cells. ${ }^{16} \mathrm{PI} 3 \mathrm{~K}$ converts $\mathrm{PIP}_{2}$ into $\mathrm{PIP}_{3},{ }^{13}$ then Akt will be attracted by $\mathrm{PIP}_{3}$ and phosphorylated by phosphoinositide-dependent protein kinase (PDK), which subsequently causes alteration of numerous cell functions including the activation of mTOR and its substrates. ${ }^{16}$
Current results showed that Survivin induced mTOR phosphorylation at Ser2448 in a concentration dependent manner. By pretreatment of Perifosine, an Akt inhibitor, the mTOR phosphorylation was diminished, suggesting that Akt was the upstream of Survivin-induced mTOR phosphorylation. In Survivin S81A-infected L929 cells, the mTOR phosphorylation bands were not clearly seen as well.

Previously we reported that Survivin induced PKA/ PI3K. ${ }^{3,8}$ Hence, by combining with current results, we suggest signaling pathway of Survivin/PKA/PI3K/Akt/ mTOR. This signaling pathway could serve as a survival pathway in L929 cells that attenuated TRAIL's potential in inducing apoptosis. ${ }^{7}$ In addition Ser81 phosphorylation site of Survivin played an important role in activating the signaling pathway. Taken together, our current results suggest that Ser81 Survivin play an important role in inducing PKA/PI3K/Akt/mTOR survival signaling pathway. Further investigation is necessary to disclose other potential downstream of Survivin/PKA/PI3K-regulated Akt.

\section{References}

1. Athanasoula KCh, Gogas H, Polonifi K, Vaiopoulos AG, Polyzos A, Mantzourani M. Survivin Beyond Physiology: Orchestration of Multistep Carcinogenesis and Therapeutic Potentials. Cancer Lett. 2014; 347(2): 175-82.

2. Altieri DC. Survivin - The inconvenient IAP. Semin Cell Dev Biol. 2015; 39: 91-6.

3. Sandra F, Khosravi-Far R. Phosphorylated-survivin at Ser81 Induced Protein Kinase A (PKA): A Back Loop. Indones Biomed J. 2011; 3(2): $138-42$

4. Fernández JG, Rodríguez DA, Valenzuela M, Calderon C, Urzúa U, Munroe D, et al. Survivin Expression Promotes VEGF-induced Tumor Angiogenesis via PI3K/Akt Enhanced $\beta$-catenin/TcfLef Dependent Transcription. Mol Cancer. 2014; 13: 209. doi: 10.1186/1476-4598-13-209.

5. Sanhueza C, Wehinger S, Castillo Bennett J, Valenzuela M, Owen GI, Quest AF. The Twisted Survivin Connection To angiogenesis. Mol Cancer. 2015; 14: 198. doi: 10.1186/s12943-015-0467-1.

6. Zhou S, Li L, Jian X, Ou X, Jiang H, Yao Z, et al. The Phosphorylation of Survivin Thr34 by p34cdc2 in Carcinogenesis of Oral Submucous Fibrosis. Oncol Rep. 2008; 20(5): 1085-91.

7. Sandra F, Khosravi-Far R. Survivin S81A Enhanced TRAIL's Activity in Inducing Apoptosis. Indones Biomed J. 2010; 2(3): 113-7.

8. Sandra F, Khosravi-Far R. Ser81 Survivin Induced Protein Kinase A (PKA)-dependent Phosphatidylinositol 3-Kinase (PI3K) Activity. Indones Biomed J. 2014; 6(3): 157-62.

9. Qiu Y, Li X, Yi Bin, Zheng J, Peng Z, Zhang Z, et al. Protein Phosphatase PHLPP Induces Cell Apoptosis and Exerts Anticancer Activity by Inhibiting Survivin Phosphorylation and Nuclear Export in Gallbladder Cancer. Oncotarget. 2015; 6(22): 19148-62.

10. Ma WH, Liu YC, Xue ML, Zheng Z, Ge YL. Downregulation of Survivin Expression Exerts Antitumoral Effects on Mouse Breast Cancer Cells in vitro and in vivo. Oncol Lett. 2016; 11(1): 159-167. 
11. Pannone G, Bufo P, Serpico R, Rubini C, Zamparese R, Corsi F, et al. Survivin Phosphorylation and M-phase Promoting Factor in Oral Carcinogenesis. Histol Histopathol. 2007; 22(11): 1241-9.

12. Delacour-Larose M, Thi MN, Dimitrov S, Molla A. Role of Survivin Phosphorylation by Aurora B in Mitosis. Cell Cycle. 2007; 6(15): 1878-85.

13. Blanco-Aparicio C, Renner O, Leal JF, Carnero A. PTEN, More Than the AKT Pathway. Carcinogenesis. 2007; 28(7): 1379-86.
14. Zhang S, Yu D. PI(3)king Apart PTEN's Role in Cancer. Clin Cancer Res. 2010; 16(17): 4325-30.

15. Lunardi A, Webster KA, Papa A, Padmani B, Clohessy JG, Bronson RT, et al. Role of Aberrant PI3K Pathway Activation in Gallbladder Tumorigenesis. Oncotarget. 2014; 5(4): 894-900.

16. Chang L, Graham PH, Ni J, Hao J, Bucci J, Cozzi PJ, et al. Targeting $\mathrm{PI} 3 \mathrm{~K} / \mathrm{Akt} / \mathrm{mTOR}$ Signaling Pathway in The Treatment of Prostate Cancer Radioresistance. Crit Rev Oncol Hematol. 2015; 96(3): 50717. 